匀, 纯度高, 晶形为非晶态。实验使用的 $\mathrm{Si}_{3} \mathrm{~N}_{4}$ 样品含氮 $37 \%$, 吸附氧 $2 \%$, 平均粒径 约 $12 \mathrm{~nm}$.

激光制粉得来的 $\mathrm{Si}_{3} \mathrm{~N}_{4}$ 纳米粒子平均粒 径一般大于 $10 \mathrm{~nm}$, 超声分散后, 仍有团聚。 为减小尺寸和粉碎团聚，我们用 $\mathrm{HF}$ 酸腐蚀 $\mathrm{Si}_{3} \mathrm{~N}_{4}$ 样品, 其中 $\mathrm{HF}$ 酸电解质由分析纯 $40 \% \mathrm{HF}$ 酸和分析纯酒精或纯水组成。使用 酒精时, 获得的样品中含有少量不溶于酒精 的 $\left(\mathrm{NH}_{4}\right)_{2} \mathrm{SiF}_{6}$. 使用纯水时, 经过几次洗涤, 能获得较纯的样品. 腐蚀后, 从 TEM 照片能 明显看出尺寸减小，团聚消失，样品颗粒大小 均匀, 平均粒径约 $6 \mathrm{~nm}$. 电子衍射图样与 $\alpha-$ $\mathrm{Si}_{3} \mathrm{~N}_{4}$ 的衍射数据一致. 这说明非昆氮化硅 纳米粒子在被腐蚀的同时有晶化的趋势。

我们采用吸收光谱法研究量子限制效 应. 测量仪器为 HIT ACHI-U3410 分光光 度计, 样品为 $\mathrm{Si}_{3} \mathrm{~N}_{4}$ 粒子有机溶剂悬胶。

末经 $\mathrm{HF}$ 酸处理的非晶 $\mathrm{Si}_{3} \mathrm{~N}_{4}$ 纳米粒 子(平均粒径 $12 \mathrm{~nm}$ ) 在 $225 \mathrm{~nm}, 282 \mathrm{~nm}$ 和 328 $\mathrm{nm}$ 处有吸收峰. 当溶剂为正已烷时, 吸收峰 最明显. 改用酒精作溶剂时, $282 \mathrm{~nm}, 328 \mathrm{~nm}$ 处的吸收峰减弱, 只有微弱的波包. 同一样 品经 $\mathrm{HF}$ 酸腐蚀后 (平均粒径 $6 \mathrm{~nm}$ ), 吸收 峰明显蓝移. $225 \mathrm{~nm}$ 处的吸收峰蓝移至 $210 \mathrm{~nm}$. $222 \mathrm{~nm}$ 和 $295 \mathrm{~nm}$ 处的凸起对应于 腐蚀前 $282 \mathrm{~nm}$ 和 $328 \mathrm{~nm}$ 处的吸收峰。
$\mathrm{Si}_{3} \mathrm{~N}_{4}$ 非晶块体的吸收系数从可见到近 紫外单调上升 ${ }^{[3]}$. 上述结果表明, $\mathrm{Si}_{3} \mathrm{~N}_{4}$ 纳米 粒子在相应波段出现吸收峰。且粒度减小 时, 吸收峰蓝移, 光致茨光的激发谱也出现 了类似的吸收峰 ${ }^{[4]}$. 我们还把结果和 Rober tson 计算出的杂质态密度 ${ }^{[9]}$ 作了比较, 但峰 的位置和宽度与 $\mathrm{O}, \mathrm{H}, \mathrm{C}$ 等杂质不同。所以 这些吸收峰是尺寸效应, 即量子限制效应的 结果.

非晶 $\mathrm{Si}_{3} \mathrm{~N}_{4}$ 纳米粒子在 $\mathrm{HF}$ 电解质中晶 化是非常有意义的新现象。这说明粒径几个 纳米时, 非鼠 $\mathrm{Si}_{3} \mathrm{~N}_{4}$ 纳米粒子是不稳定的, 其 中的原子比在大块固体中有更大的自由度。 因此,由于巨大的表面压力和 $\mathrm{F}^{-}$与 $\mathrm{Si}, \mathrm{N}$ 原 子间的强烈作用，非晶 $\mathrm{Si}_{3} \mathrm{~N}_{4}$ 纳米粒子转化 为结构更稳定且不易被 HF “酸腐蚀的晶粒。

\section{参考文 献}

[1] Bawendi, M. G., Steigerwald, M. L., Brus, L. E., Annu. Rev. Phys. Chem., 1990,41:477.

[2] Hu, Y. Z., Lindberg, M., Koch, S. W. et al., SPIE 1216, 1990, 88.

[3] Philipp, H. R., J. Electrochem. Soc., 1973, 120: 295.

[4]本道火、魏雄,科学通报, 1992,37(17): 1624 。

[5] Robertson, J., Phil. Mag., 1991, B63: 47.

李道火 左都罗 (中国科学院安徽光学精密机船 研究所, 合肥 230031

\title{
新的稀土锂钒酸盐 $\left[\mathrm{Y}_{0.5-\mathrm{x}} \mathrm{Li}_{1.5} \mathrm{VO}_{4}:\left(\mathrm{Dy}^{3+}, \mathrm{Eu}^{3+}\right)_{x}\right]$ 多波段发光*
}

本文首次报道了新的稀土锂钒酸盐 $\mathrm{Y}_{0.5-x} \mathrm{Li}_{1.5} \mathrm{VO}_{4}:\left(\mathrm{Dy}^{3+}, \mathrm{Eu}^{3+}\right)_{x}$ 多晶粉末的制 备,多波段发光和结构。

样品的制备是采用稀土氧化物 $\left(\mathrm{Y}_{2} \mathrm{O}_{3}\right.$ $\mathrm{Dy}_{2} \mathrm{O}_{3}$ 和 $\mathrm{Eu}_{2} \mathrm{O}_{3}$ ) 纯度为 $99.99 \%$ 与光谱纯 的 $\mathrm{V}_{2} \mathrm{O}_{5}$ 和 $\mathrm{Li}_{2} \mathrm{CO}_{3}$ 按化学计量比混 匀, 在 $600^{\circ} \mathrm{C}$ 焙烧数小时合成出系列 $\mathrm{Y}_{0.5-x} \mathrm{Li}_{1.5} \mathrm{VO}_{4}$ : $\left(\mathrm{Dy}^{3+}, \mathrm{Eu}^{3+}\right)_{x}(0.01<x<0.1 \mathrm{~mol})$ 样品, 比通常钒酸盐合成温度降低 $400^{\circ} \mathrm{C}$.

室温下测定了 $\mathrm{Y}_{0.44} \mathrm{Li}_{1.5} \mathrm{VO}_{4}: \mathrm{Dy}_{0.05} \mathrm{Eu}_{0.03}$

*稀土化学与物理开放实验室基金资助课题. 


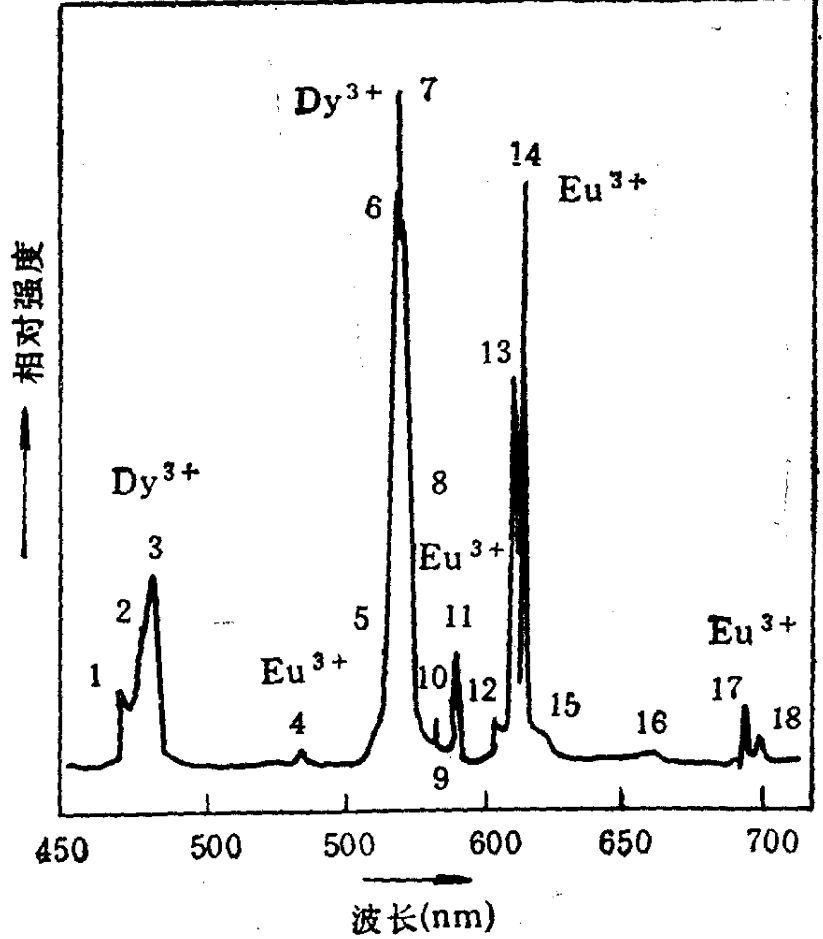

图 $1 \mathrm{Y}_{0,44} \mathrm{Li}_{1,5} \mathrm{VO}_{4}: \mathrm{DY}_{0.03} \mathrm{Eu}_{0.01}$ 样品的苂光光谱

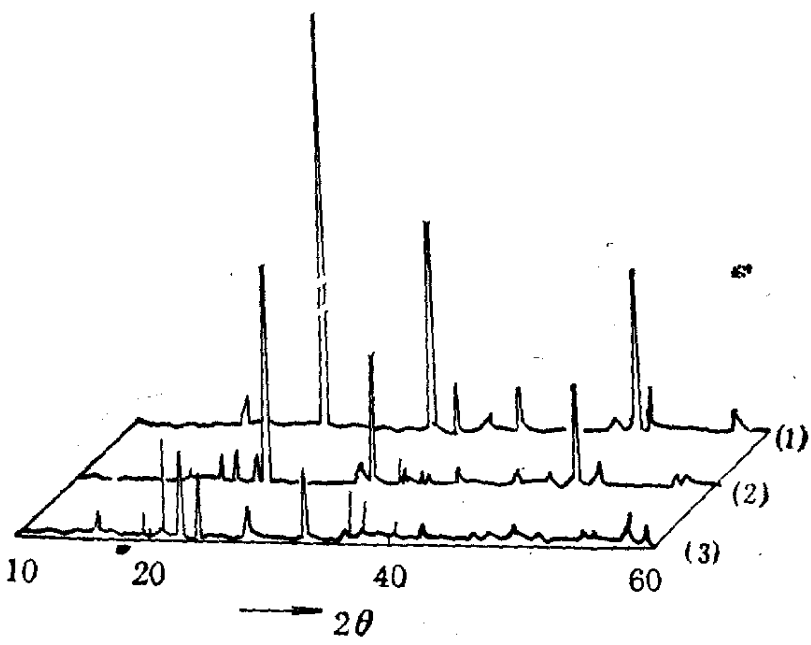

图 $2 \mathrm{X}$ 射线粉末行射谱图

(1) $\mathrm{YVO}_{4}$; (2) $\mathrm{Y}_{0.5 \sim x}, \mathrm{Li}_{1.5} \mathrm{VO}_{4}$ :(Dy, Eu ) ; (3) $\mathrm{Li}_{3} \mathrm{VO}_{4}$ 样品的激发光谱和苂光光谱（见 图 1)。激发 光谱中在紫外区出现很强的带状发射, 峰值 在 322.4-324.4nm，是 $\mathrm{VO}_{4}^{3-}$ 基团的发射带。 用 $322.4 \mathrm{~nm}$ 激发 $\mathrm{Y}_{0.44} \mathrm{Li}_{1.5} \mathrm{VO}_{4}: \mathrm{Dy}_{0.05} \mathrm{Eu}_{0.01}$ 样 品, 得到可见区多波段荧光峰群. 第一组是 由 $474.2,482.0$ 和 $484.2 \mathrm{~nm}$ 三个可分辨的峰
组成, 源于 $D_{y}{ }^{3+}$ 的 ${ }^{4} F_{9 / 2} \rightarrow{ }^{6} \mathrm{H}_{15 / 2}$ 跃迁在 蓝区的苂光发射.第二组在黄区,由569， 571 、574 和 $576.4 \mathrm{~nm}$ 四个峰组成, 是最 强的一组，茨光峰值在 $574 \mathrm{~nm}$. 第三组 在红区由 $608,614.4 ， 619.2$ 和 $626 \mathrm{~nm}$ 组成的, 强度仅次于黄区。这两组黄区 最强和红区次强的苂光峰群是分别来自 于 $\mathrm{Dy}^{3+}$ 的 ${ }^{4} \mathrm{~F}_{9 / 2} \rightarrow{ }^{6} \mathrm{H}_{13 / 2}$ 跃迁和 $\mathrm{Eu}^{3+}$ 的 ${ }^{5} \mathrm{D}_{0} \rightarrow{ }^{7} \mathrm{~F}_{2}$ 电偶极跃迁. 以上二个组 态都是 $\Delta J=2$, 为超敏跃迁. 第四组 橙色区是由 $586,591.2$ 和 $593.6 \mathrm{~nm}$ 组 成。第五组是由 697.4 和 $702 \mathrm{~nm}$ 构成。 这两组荧光强度较弱。是来自 $\mathrm{Eu}^{3+}$ 的 ${ }^{5} \mathrm{D}_{0} \rightarrow{ }^{7} \mathrm{~F}_{1},{ }^{7} \mathrm{~F}_{4}$ 跃迁发射。很有兴趣的是 还观查到了 ${ }^{5} D_{1} \rightarrow{ }^{7} F_{0}$ 跃迁的荧光 发 射 在 $538 \mathrm{~nm}$ 处.

$\mathrm{VO}_{4}^{3-}$ 基团在 $322.4 \mathrm{~nm}$ 发射峰相当 强, 它的发光机制可能是钥酸根吸收了 激发能, 然后通过电荷迁移过程使钒酸 根激发, 即 $\left[\mathrm{V}^{5+} \mathrm{O}_{4}^{-2 n}\right] \rightarrow\left[\mathrm{V}^{4+} \mathrm{O}_{4}^{-2 n+1}\right]$ 体 系接收能量后, 氧的最高轨道上的电子 跃迁进人钒的最低空轨䢥, 使钒酸根受 激发, 同时将能量传给 $\mathrm{R}^{3+}$. 实验中观 测到用 $322.4 \mathrm{~nm}$ 激发与用 $\mathrm{Dy}^{3+}\left(\right.$ 或 $\mathrm{Eu}^{3+}$ $393 \mathrm{~nm})$ 的特征激发峰 $353.4 \mathrm{~nm}$ 激发, 茨光强度前者远远大于后者. 证明了发 生 $\left[\mathrm{V}^{5+} \mathrm{O}_{4}^{-2 n}\right] \rightarrow\left[\mathrm{V}^{4+} \mathrm{O}_{4}^{-2 n+1}\right] \rightarrow \mathrm{R}^{3+}$ 传 能过程。

$\mathrm{X}$ 射线分析结果 (见图 2) 表明, $\mathrm{Y}_{0.5-x} \mathrm{Li}_{\mathrm{1} .5} \mathrm{VO}_{4}:\left(\mathrm{Dy}^{3+}, \mathrm{Eu}^{3+}\right)_{x}(0.01<x<$ $0.1 \mathrm{~mol})$ 样品的结构是由 $\mathrm{YVO}_{4}$ 和 $\beta_{11}-\mathrm{Li}_{3} \mathrm{VO}_{4}$ 二种结构组成的。

于亚勤宋明淑

（中国科学院长春应用化学研究所，长春 130022）

宋小羽

（长春师范学院，长春 130023) 